\title{
Análise das Leis Ambientais Brasileiras e sua Interface com os Objetivos do Desenvolvimento Sustentável - ODS
}

Analysis of Brazilian Environmental Laws and their Interface with the Sustainable Development Goals - SDG

Análisis de las leyes ambientales brasileñas y su interfaz con los Objetivos de Desarrollo Sostenible ODS

\section{Resumo}

A legislação ambiental brasileira constitui-se um elemento estratégico para o alcance do desenvolvimento sustentável, tendo em vista ser o principal instrumento de comando e controle que o Estado possui para regular as atividades produtivas e econômicas em geral, ao estabelecer os limites e normas na relação público-privado. Neste sentido, o trabalho objetivou analisar as principais leis ambientais brasileiras, apontando sua interface com os Objetivos do Desenvolvimento Sustentável, propostos pela Organização das Nações Unidas, e suas metas. Espera-se contribuir com futuros trabalhos nessa área, dada a jovialidade do tema, além de possibilitar um olhar mais objetivo sobre o assunto, utilizando-se como parâmetros os Objetivos de Desenvolvimento Sustentável que servirão de base para identificar os que se aproximam mais das questões ambientais, no sentido de contribuir para o alcance do desenvolvimento sustentável. Palavras-chave: Legislação ambiental; ODS; Sustentabilidade.

\begin{abstract}
Brazilian environmental legislation is a strategic element for the achievement of sustainable development, in view of being the main command and control instrument that the State has to regulate productive and economic activities in general, by establishing the limits and norms in the relationship public-private. In this sense, the work aimed to analyze the main Brazilian environmental laws, pointing out their interface with the Sustainable Development Goals, proposed by the United Nations, and their goals. It is expected to contribute to future work in this area, given the joviality of the theme, in addition to enabling a more objective look at the subject, using as parameters the Sustainable Development Goals that will serve as a basis to identify those who come closest to the issues to contribute to the achievement of sustainable development.
\end{abstract}

Keywords: Environmental legislation; SDG; Sustainability.

\begin{abstract}
Resumen
La legislación ambiental brasileña es un elemento estratégico para el logro del desarrollo sostenible, en vista de ser el principal instrumento de mando y control que tiene el Estado para regular las actividades productivas y económicas en general, estableciendo los límites y normas en la relación público-privada. En este sentido, el trabajo tuvo como objetivo analizar las principales leyes ambientales brasileñas, señalando su interfaz con los Objetivos de Desarrollo Sostenible, propuestos por Naciones Unidas, y sus metas. Se espera que contribuya al trabajo futuro en esta área, dada la jovialidad del tema, además de posibilitar una mirada más objetiva al tema, utilizando como parámetros los Objetivos de Desarrollo Sostenible que servirán de base para identificar a quienes más se acercan. a los temas para contribuir al logro del desarrollo sostenible.
\end{abstract}

Palabras clave: Legislación ambiental; ODS; Sustentabilidad.

\section{Introdução}

Os Objetivos do Desenvolvimento Sustentável - ODS, que compõem a Agenda 2030, foram lançados em 2015, pela 
ONU (Nações Unidas, 2015), para acabar com a pobreza, proteger o meio ambiente e o planeta, bem como assegurar a prosperidade para todas as nações (ONU, 2015). Os ODS representam o núcleo da Agenda e deverão ser alcançados até o ano 2030.

O documento foi assinado por 193 países-membros das Nações Unidas (ONU) e contém 17 objetivos e 169 metas que identificam as prioridades globais de desenvolvimento sustentável e refletem, ao mesmo tempo, o compromisso oficial do mundo com a erradicação da pobreza extrema, reconhecendo, também, a necessidade de operar dentro dos limites ecológicos do planeta.

Segundo o Relatório Brundtland, intitulado: "O Nosso Futuro Comum", "o desenvolvimento sustentável atende às necessidades do presente sem comprometer a capacidade das gerações futuras de atender às suas próprias necessidades" (Comissão Mundial sobre Meio Ambiente e Desenvolvimento, 1988). A comissão destaca que "um planeta esgotado não será capaz de fornecer os insumos físicos necessários para as gerações futuras".

Assim, para avançar no desenvolvimento e torná-lo realidade, os países devem trabalhar em prol de todos os 17 ODS, conforme orienta a Agenda (Plataforma Agenda 2030, 2020), pois eles são integrados e indivisíveis. Nesse sentido, o desenvolvimento sustentável tem conduzido os países que integram a Organização das Nações Unidas (ONU) a constantes desafios, uma vez que deverão se esforçar para buscar o equilíbrio entre as três dimensões do desenvolvimento sustentável: a econômica, a social e a ambiental.

Esta definição de desenvolvimento sustentável é reconhecida nas bases internacionais como a WWF, IUCN e PNUMA, respectivamente: "melhorar a qualidade de vida humana enquanto vive dentro da capacidade de suporte de ecossistemas" [WWF (Fundo Mundial para a Natureza), IUCN (Internacional Union for Conservation of Nature), e UNEP (United Nations Environment Program), 1991].

Com o passar dos anos, observa-se, no entanto, que alguns fatores como o uso ecológico excessivo, a perda de biodiversidade, nitrificação excessiva e mudanças climáticas, vêm afetando a capacidade dos recursos naturais, comprometendo os limites naturais do nosso planeta e ganharam mais destaque através da meta do Acordo Climático de Paris de 2015 de não exceder $2^{\circ} \mathrm{C}$ de aquecimento em relação às temperaturas pré-industriais, que são de, aproximadamente, $1,5^{\circ} \mathrm{C}$ (UNFCCC, 2015).

Além disso, o uso abusivo dos ecossistemas do planeta, pela humanidade, indica uma sobrecarga na capacidade disponível dos nossos recursos. As estimativas mais recentes, provavelmente conservadoras, indicam que a demanda da humanidade excede a capacidade disponível em mais de 68\% (Borucke et al., 2013).

Diante desse cenário, em 2017, a Rede WWF desenvolveu uma estratégia global, que abrange o período até 2030, com o propósito de alterar a trajetória das curvas de perda de biodiversidade e do aumento das emissões de gases de efeito estufa (GEE) e conter a extinção de espécies e o desaparecimento de ecossistemas, assim como mitigar os principais causadores das mudanças climáticas (Rede WWF, 2017).

No Brasil, as leis que tratam do meio ambiente estão entre as mais completas e avançadas do mundo. No entanto, de acordo com o III Relatório Luz, da Sociedade Civil da Agenda 2030 de Desenvolvimento Sustentável, lançado em 2019, pelo Grupo de Trabalho da Sociedade Civil para a Agenda 2030 (GT Agenda 2030), o acirramento das violações e o desrespeito aos direitos sociais, ambientais e econômicos em curso no Brasil coloca o país cada vez mais distante do caminho do desenvolvimento sustentável.

O Relatório mostra, ainda, que os retrocessos que vêm sendo promovidos no país agravam, principalmente, a vida das mulheres negras, das quilombolas e das indígenas, sem apresentar soluções para pacificar o país; diminui a transparência e os espaços de diálogo; e favorece forte tendência de que a judicialização firme-se como estratégia para a garantia de direitos (Relatório Luz, 2019).

Além desses problemas que afetam a população, principalmente as mais vulneráveis, outros temas voltados ao Meio Ambiente são apontados no referido documento, como por exemplo, a liberação de novos agrotóxicos, por parte do Ministério 
do Meio Ambiente, os desastres ambientais ocorridos em Minas Gerais, nos anos de 2015 e 2019, respectivamente, o que demonstra nosso distanciamento cada vez maior do plano de ação mundial que compõe os ODS, ferindo a cartilha do desenvolvimento sustentável, defendida e assinada por 193 países, incluindo o Brasil, nas Nações Unidas em 2015.

Essa realidade despertou-nos o interesse de realizar uma leitura minuciosa das principais leis ambientais brasileiras, destacando o principal objetivo de cada uma, sua natureza e principais conclusões, a fim de verificar a relação destas com o compromisso assumido pelo governo brasileiro, junto à Organização das Nações Unidas (ONU), de alcançar os 17 Objetivos do Desenvolvimento Sustentável até 2030, bem como se houve alguma atualização na referida legislação, no período pós-2015, visando o alinhamento com os 17 ODS.

É importante ressaltar que as leis ambientais são criadas com o intuito de proteger o meio ambiente e minimizar as consequências de ações que degradam o meio ambiente, todavia, a falta de conscientização da população, para o tema, e a baixa fiscalização são os principais fatores que influenciam negativamente nossa situação.

Portanto, esta pesquisa justifica-se pela relevância em apresentar uma visão abrangente do panorama atual em torno da legislação ambiental brasileira e sua interface com os Objetivos do Desenvolvimento Sustentável (ODS).

\section{Metodologia}

Este estudo caracteriza-se como uma pesquisa documental, descritiva e qualitativa (Pereira et al., 2018) sobre as leis ambientais brasileiras e suas relações diretas e indiretas com os objetivos do desenvolvimento sustentável, também conhecidos como ODS.

Desta feita, concebeu-se uma relação direta de implicação da legislação na perquirição da vida humana, visto que esta está intimamente ligada à natureza e completamente dependente desta, e o bem-estar social, garantido constitucionalmente, assegura um ambiente livre para viver, além de qualidade física e mental.

Assim, a partir da leitura das dezessete principais leis ambientais em vigor no Brasil, analisou-se como cada uma destas se encaixa com os ODS da Agenda 2030 da ONU. Como explicitado no site do Planalto: "a própria Resolução da ONU prevê a possibilidade de cada país decidir sobre a forma de implementação da Agenda em seu território". Assim, apesar de o Brasil continuar vinculado às obrigações que assumiu, por uma própria questão de soberania, pode determinar como realizar tais ações em seu território.

Apesar de nenhuma das leis citadas ter sido modificada, em função dos ODS, pode-se inferir que elas possuem uma harmonia com tais objetivos. Essa situação explicita que não haveria a necessidade de uma mudança legislativa, mas sim, da melhoria nas ações governamentais para que os objetivos sejam alcançados. As leis que serviram de base para este estudo foram organizadas de forma cronológica, para uma melhor observação do desenvolvimento do Direito Ambiental brasileiro, ao longo das últimas décadas.

\section{Resultados e Discussão}

A partir dos objetivos propostos pelos ODS, bem como suas metas, observa-se que, nem todos se relacionam diretamente com o da dimensão ambiental, embora se reconheça que eles são integrados e indivisíveis.

O Quadro 1 mostra como os 17 Objetivos mesclam, de forma equilibrada, as principais dimensões do desenvolvimento sustentável: a social, a econômica, a ambiental e a institucional. 
Quadro 1 - Relação dos ODS com as dimensões do desenvolvimento sustentável.

\begin{tabular}{|c|c|}
\hline $\begin{array}{l}\text { Dimensões do } \\
\text { desenvolvimento } \\
\text { sustentável }\end{array}$ & Objetivos do Desenvolvimento Sustentável \\
\hline Dimensão social & $\begin{array}{l}\text { ODS } 1 \text { - Acabar com a pobreza em todas as suas formas, em todos os lugares. } \\
\text { ODS } 2 \text { - Acabar com a fome, alcançar a segurança alimentar e melhoria da nutrição e } \\
\text { promover a agricultura sustentável. } \\
\text { ODS } 3 \text { - Garantir uma vida saudável e promover o bem-estar de todos em todas as idades. } \\
\text { ODS } 4 \text { - Assegurar a educação inclusiva e equitativa e de qualidade, e promover } \\
\text { oportunidades de aprendizagem ao longo da vida para todos. } \\
\text { ODS } 5 \text { - Alcançar a igualdade de gênero e empoderar todas às mulheres e meninas. } \\
\text { ODS } 10 \text { - Reduzir a desigualdade dentro dos países e entre eles. }\end{array}$ \\
\hline $\begin{array}{l}\text { Dimensão } \\
\text { econômica }\end{array}$ & $\begin{array}{l}\text { ODS } 7 \text { - Garantir acesso à energia barata, confiável, sustentável e renovável para todos. } \\
\text { ODS } 8 \text { - Promover o crescimento econômico sustentado, inclusivo e sustentável, emprego } \\
\text { pleno e produtivo, e trabalho decente para todos. } \\
\text { ODS } 9 \text { - Construir infraestrutura resiliente, promover a industrialização inclusiva e } \\
\text { sustentável, e fomentar a inovação. } \\
\text { ODS } 12 \text { - Assegurar padrões de produção e de consumo sustentáveis. }\end{array}$ \\
\hline $\begin{array}{l}\text { Dimensão } \\
\text { ambiental }\end{array}$ & $\begin{array}{l}\text { ODS } 6 \text { - Garantir disponibilidade e manejo sustentável da água e saneamento para todos. } \\
\text { ODS } 11 \text { - Tornar as cidades e os assentamentos humanos inclusivos, seguros, resilientes e } \\
\text { sustentáveis. } \\
\text { ODS } 13 \text { - Tomar medidas urgentes para combater a mudança do clima e seus impactos. } \\
\text { ODS } 14 \text { - Conservação e uso sustentável dos oceanos, dos mares e dos recursos marinhos } \\
\text { para o desenvolvimento sustentável. } \\
\text { ODS } 15 \text { - Proteger, recuperar e promover o uso sustentável dos ecossistemas terrestres, gerir } \\
\text { de forma sustentável as florestas, combater a desertificação, deter e reverter à degradação da } \\
\text { terra e deter a perda de biodiversidade. }\end{array}$ \\
\hline $\begin{array}{l}\text { Dimensão } \\
\text { institucional }\end{array}$ & $\begin{array}{l}\text { ODS } 16 \text { - Promover sociedades pacíficas e inclusivas para o desenvolvimento sustentável, } \\
\text { proporcionar o acesso à justiça para todos e construir instituições eficazes, responsáveis e } \\
\text { inclusivas em todos os níveis. } \\
\text { ODS } 17 \text { - Fortalecer os meios de implementação e revitalizar a parceria global para o } \\
\text { desenvolvimento sustentável. }\end{array}$ \\
\hline
\end{tabular}

Fonte: ONU (2015). Elaboração: Ipea.

Observa-se que, entre os dezessete ODS, seis estabelecem uma relação mais direta com a dimensão social: ODS 1, 2, 3, 4, 5 e 10, embora, indiretamente, relacionem-se, também, com a dimensão ambiental. Quatro, relacionam-se com a dimensão econômica, a saber: os ODS 7, 8, 9 e 12. Os vinculados à dimensão ambiental são cinco: ODS 6, 11, 13, 14 e 15. Já os ODS 16 e 17, por sua vez, dialogam com a dimensão institucional do desenvolvimento sustentável e remetem à necessidade de adoção de estratégias e políticas adequadas, de recursos disponíveis e de outros meios fundamentais para a implementação dos objetivos. Vale destacar que o ODS 5 é o único que não apresenta interface com as leis aqui analisadas. Tal objetivo, relaciona-se, mais 
diretamente, com a dimensão social.

Alguns objetivos a serem cumpridos pelo Brasil, até 2030, são classificados como ousados, como é o caso do ODS 01, que visa "Acabar com a pobreza em todas as suas formas, em todos os lugares". De acordo com dados do IPEA, é praticamente impossível reduzir a zero o número de pobres, qualquer que seja a linha de pobreza, além disso, a erradicação da pobreza extrema será atingida quando o percentual da população nesta condição estiver abaixo de 3\% (IPEA, 2018).

Além disso, o ODS 01 coaduna-se com a Lei da Política Agrícola, uma vez que busca, dentre suas metas, garantir que todos os homens e mulheres tenham direitos iguais aos recursos naturais, dentre outros, além de construir a resiliência dos pobres e daqueles em situação de vulnerabilidade, e reduzir a exposição e vulnerabilidade destes a eventos extremos relacionados com o clima e outros choques e desastres econômicos, sociais e ambientais.

Os problemas ambientais que o planeta vem enfrentando, nos últimos anos, exigem mudanças em todos os outros setores. Nesse sentido, o conjunto de leis que rege o sistema ambiental também precisam ser revistas, no sentido de atender às exigências dos desafios atuais em prol do desenvolvimento sustentável.

No entanto, é importante perceber que não houve, no decorrer dos anos, uma sucessão cronológica na elaboração das leis, porém, a cada novo problema ou demanda relacionada a aspectos ambientais, uma nova legislação foi criada, produzindo regras capazes de atender às exigências impostas pelas questões ambientais que surgissem. Nesse sentido, compreendemos que os ODS devem estar alinhados à realidade, às restrições de recursos e das mudanças climáticas, além de outras questões relacionadas ao meio ambiente.

As leis ambientais definem normas e infrações como o critério do agente-pagador e ressalta a antevisão da legislação brasileira na co-responsabilidade dos ODS. Afinal, há um processo de mudança de comportamento na sociedade civil que não está associado apenas às eventuais penalidades legais, mas à adoção de uma postura de responsabilidade compartilhada entre todos para vencer os desafios ambientais, que já vivenciadas.

O Quadro 2, a seguir, mostra a relação das leis ambientais brasileiras com os 17 ODS inseridos na Agenda 2030 da ONU. 
Quadro 2 - As leis ambientais brasileiras e sua relação com os ODS.

\begin{tabular}{|c|c|}
\hline Legislação Ambiental Brasileira & $\begin{array}{l}\text { Agenda } 2030 \text { - Objetivos do } \\
\text { Desenvolvimento Sustentável }\end{array}$ \\
\hline $\begin{array}{l}\text { - } \quad \text { Lei do Patrimônio Cultural - Decreto-Lei n }{ }^{\circ} 25 \text {, de } \\
30 / 11 / 1937\end{array}$ & ODS 4 \\
\hline - Lei da Fauna Silvestre - no 5.197 de 03/01/1967 & ODS $7,8,14$ e 15 \\
\hline - Lei das Atividades Nucleares - $\mathrm{n}^{0}$ 6.453, de 17/10/1977 & ODS 7 \\
\hline - Lei do Parcelamento do Solo Urbano - nº 6.766 de 19/12/1979 & ODS 11 \\
\hline $\begin{array}{l}\text { - Lei do Zoneamento Industrial nas Áreas Críticas de Poluição - } \mathrm{n}^{\circ} \\
6.803 \text { de } 02 / 07 / 1980\end{array}$ & ODS 9 \\
\hline - Lei da Área de Proteção Ambiental (APA) - nº 6.902 de 27/04/1981 & ODS 14 \\
\hline - Lei da Política Nacional do Meio Ambiente - no 6.938 de 17/01/1981 & ODS $3,4,6,9,11,13$ e 15 \\
\hline - Lei da Ação Civil Pública - no 7.347, de 24/07/1985 & ODS 3 e 16 \\
\hline - Lei do Gerenciamento Costeiro - $\mathrm{n}^{\circ} 7.661$ de 16/05/1988 & ODS $3,6,7,11,14,15$ e 16 \\
\hline - Lei da criação do IBAMA - n. 7.735 de 22/02/1989 & ODS $1,6,7,13,14$ e 15 \\
\hline - Lei dos Agrotóxicos - nº 7.802 de 10/07/1989 & ODS $2,3,8$ e 12 \\
\hline Lei da Exploração Mineral - nº 7.805 de 18/07/1989 & ODS $8,9,14$ e 15 \\
\hline - Lei da Política Agrícola - no 8.171 de 17/01/1991 & $\begin{array}{l}\text { ODS } 1,2,3,6,7,8,9,10,11,12, \\
14 \text { e } 15\end{array}$ \\
\hline Lei de Recursos Hídricos - nº 9.433 de 08/01/1997 & ODS 6 e 14 \\
\hline - Lei de Crimes Ambientais - $\mathrm{n}^{\circ} 9.605$ de 12/02/1998 & ODS 13,14 e 15 \\
\hline $\begin{array}{l}\text { - Lei da Engenharia Genética - no 8.974, de 05/01/1995 (Revogada } \\
\text { pela Lei de Biossegurança n } n^{\circ} 11.105 \text {, de } 24 \text { de março de 2005) }\end{array}$ & ODS $2,3,12$ e 17 \\
\hline $\begin{array}{l}\text { - Lei das Florestas - n. } 4.771 \text { de 15/09/1965 (Revogada pelo Novo } \\
\text { Código Florestal Brasileiro - n. 12.651, de 25/05/2012) }\end{array}$ & ODS $11,13,14$ e 15 \\
\hline
\end{tabular}

Fonte: Autores (2021).

A partir das leituras realizadas no decorrer do trabalho, observamos que, no rol das leis aqui analisadas, a Lei das Florestas - n. 4.771 de 15/09/1965, foi revogada em 25/05/2012, pelo Novo Código Florestal Brasileiro - n. 12.651. Seu texto original foi modificado em alguns pontos pela Lei no 12.727 de 17 de outubro de 2012 em que algumas regulamentações foram dadas pelo Decreto no. 7.830 de 17 de outubro de 2012 (EMBRAPA, 2020).

Uma das inovações da Lei foi a criação do Cadastro Ambiental Rural (CAR) e a previsão de implantação do Programa de Regularização Ambiental (PRA) nos Estados e no Distrito Federal. O reconhecimento da existência de áreas rurais consolidadas em Áreas de Preservação Permanente, de Reserva Legal ou de Uso Restrito também foi um ponto de destaque na aplicação da nova Lei (EMBRAPA, 2020).

Além desta, a Lei da Engenharia Genética - no 8.974, de 05/01/1995, também fora revogada pela Lei de Biossegurança - no 11.105, em 24 de março de 2005, em função da necessidade de se estabelecer normas para o uso das técnicas de engenharia genética e liberação no meio ambiente de organismos geneticamente modificados. Desse modo, foi criado, no âmbito da Presidência da República, a Comissão Técnica Nacional de Biossegurança (CNTBio). Devido à sobreposição legal que versava sobre OGMs, em 2004, o Tribunal Regional Federal decide que a lei específica (Lei 8974/95) se sobrepõe à lei geral (Lei do 
Meio Ambiente).

Com base nos resultados, ora apresentados, espera-se poder contribuir com futuros trabalhos nessa área, dada a jovialidade do tema, além de possibilitar um olhar mais objetivo nas discussões em torno da legislação analisada, bem como dos ODS, que serviram de parâmetro para identificar os que se aproximam mais das questões que envolvem o meio ambiente, no sentido de contribuir para o tão sonhado "desenvolvimento sustentável".

\section{Considerações Finais}

De acordo com o MMA (2018), os desafios para os municípios brasileiros aderirem à Agenda 2030, para alcançar os ODS, são enormes, dada a complexidade das pautas legais que devem ser cumpridas, para alcançar, com eficiência, o bem-estar da população.

Nesse sentido, compreendemos que, para atingir o modelo de desenvolvimento sustentável, definido nos 17 ODS e suas 169 metas, será fundamental um esforço compartilhado entre União, estados, municípios, sociedade e setor privado. Esta Agenda traz os desafios de erradicar a pobreza extrema; combater a desigualdade e a injustiça e conter as mudanças climáticas. Para isso, torna-se urgente e necessário que, nos próximos 10 anos, cada município da federação defina modelos de alocação de recursos, metas locais, além de criar políticas públicas que possibilitem lidar com os objetivos definidos na Agenda, adequando-os, de acordo com cada realidade.

Conforme sugerido pela ONU 2015), cabe ao país implantar, acompanhar e avaliar o progresso alcançado, por meio de indicadores que deverão ser utilizados para a tomada de decisão, buscando superar os resultados não conquistados e reiterar o compromisso com a sustentabilidade.

Assim, a implementação de legislação que estabeleça alguma relação com os ODS, é a principal garantia de que os compromissos assumidos serão reconhecidos e trabalhados pela sociedade, de modo que o país caminhe na direção certa, buscando alcançar os compromissos assumidos, em prol do desenvolvimento sustentável e atendimento à Agenda 2030.

Vale destacar, também, que as leis ambientais brasileiras não se relacionam apenas com um tema ou um ODS específico, e isso permite que atuem em várias frentes, com múltiplos parceiros, sempre considerando os ODS em sua integralidade.

É importante lembrar que as leis aqui enumeradas são apenas parte do Direito Ambiental do País, que ainda possui inúmeras outras matérias, como decretos, resoluções e atos normativos. Há também regulamentações de órgãos comprometidos para que as leis sejam cumpridas, como é o caso do Conselho Nacional de Meio Ambiente (Conama) e do Ministério do Meio Ambiente.

Por fim, como sugestão para pesquisas futuras, propõe-se um a análise uma cruzadas dos princípios dos ODS x Metas do Milênio tendo por problemática a análise comparativa o estudo de caso da nova legislação ambiental brasileira x a legislação americana.

\section{Referências}

-Borucke, M., Moore, D., Cranston, G., Gracey, K., Iha, K., Larson, J. et al. (2013). Contabilização da procura e oferta da capacidade regenerativa da biosfera: a metodologia e estrutura subjacentes das Contas da Pegada Nacional. Ecol. Índico 24, 518-533. 10.1016/j.ecolind.2012.08.005.

Brasil. (2019). Grupo de Trabalho Agenda 2030 - III Relatório Luz Da Sociedade Civil Da Agenda 2030 De Desenvolvimento Sustentável. https://gtagenda2030.org.br/relatorio-luz/relatorio-luz-2019/.

Brundtland, G. H. (1987). Our Common Future - The World Commission on Environment and Development - Oxford University, Oxford University Press.

Comissão Mundial Sobre Meio Ambiente E Desenvolvimento (CMMAD) (1988). Nosso futuro comum. Fundação Getúlio Vargas.

Costanza, R., Fioramonti, L., \& Kubiszewski, I. (2016). The UN sustainable development goals and the dynamics of well-being. Frontiers in Ecology and the Environment, 14(2), 59-59. 
EMBRAPA. Entenda a Lei 12.651 de 25 de maio de 2012 (2020). Código Florestal: Adequação ambiental da paisagem rural. https://www.embrapa.br/codigoflorestal/entendao-codigo-florestal.

FIOCRUZ Rondônia (2020). Biossegurança; Comissão Interna de Biossegurança (CIBio). https://www.rondonia.fiocruz.br.

Gil, A. C. (2008). Como elaborar projetos de pesquisa. (4a ed.), Atlas.

Instituto Brasileiro do Meio Ambiente e dos Recursos Naturais Renováveis (Ibama). (2020). Sobre o IBAMA. https://www.gov.br/ibama/pt-br/acessoainformacao/institucional/sobre-o-ibama.

IPEA. (2015). Desafios do Desenvolvimento: Objetivos de Desenvolvimento Sustentável: metas possíveis. Ano 12. Edição 86. https://www.ipea.gov.br/ods/.

MMA. Ministério do Meio Ambiente. (2018). Lei Complementar 140. <http://www.mma.gov.br/governanca-ambiental/sistema-nacional-do-meio ambiente/leicomplementar-140.htmls.

Monosowski, E. (1989). Políticas ambientais e desenvolvimento no Brasil. Cadernos Fundap: Planejamento e Gerenciamento Ambiental, 9(16).

Nilsson, M., Griggs, D., \& Visbeck, M. (2016.). Policy: map the interactions between Sustainable Development Goals. Nature News, 534 (7607), 320.

ONU - Organização das Nações Unidas. (2015). Objetivos de Desenvolvimento Sustentável da ONU. https://sustainabledevelopment.un.org/sdgs.

ONU - Organização das Nações Unidas. (2015). Transformando nosso mundo: a Agenda 2030 para o desenvolvimento sustentável. ONU. $\langle$ https://goo.gl/jcFMVC〉.

O ECO. (2020). Entenda a Lei de Crimes Ambientais. https://www.oeco.org.br/dicionario-ambiental/28289.

Oliveira, M. M. \& Araújo, J. C. de. (2020). A política agrícola como matéria constitucional. https://www12.senado.leg.br.

Pereira et al. (2018). Metodologia da pesquisa científica, UFSM.

Plataforma Agenda 2030. (2020). Os 17 Objetivos de Desenvolvimento Sustentável. http://www.agenda2030.org.br/os ods/.

Presidência da República - Secretaria de Governo (2021). ODS - O Governo Brasileiro e a Agenda 2030. https://www.gov.br/secretariadegoverno/ptbr/assuntos/secretaria-especial-de-articulacao-social/capa/noticias/o-governo-brasileiro-e-a-agenda-2030-1.

Santos, A. S. \& Ribeiro, S. K. (2015.). The role of transport indicators to the improvement of local governance in Rio de Janeiro City: A contribution for the debate on sustainable future. Case Studies on Transport Policy, 3(4), 415-420.

SDSN (2013). Thematic Group on Sustainable Cities. Supported by UN-Habitat, UCLG, Cities Alliance, and ICLEI. Why the world needs an urban development goal. https://sustainabledevelopment.un.org/content/documents/2569130918SDSN-Why-the-World-Needs-an-Urban-SDG.pdf.

UNFCCC (2015). Acordo Climático de Paris. http://unfccc.int/files/essential_background/convention/application/pdf/english_paris_agr eement.pdf.

WWF (Fundo Mundial para a Natureza), IUCN (União Internacional para a Conservação da Natureza) e UNEP (Programa das Nações Unidas para o Meio Ambiente). (1991). Cuidando da Terra. Gland: WWF (Fundo Mundial para a Natureza), IUCN (União Internacional para a Conservação da Natureza) e UNEP (Programa das Nações Unidas para o Meio Ambiente).

Wackernagel, M., Hascom, L. \& Lin, D. (2017). Tornando os Objetivos de Desenvolvimento Sustentável consistentes com a sustentabilidade. Energy Res. https://doi.org/10.3389/fenrg.2017.00018 